\title{
Team-Based Learning and Ethics Education in Nursing
}

\author{
Susan E. Hickman, PhD; Lucia D. Wocial, PhD, RN \\ Journal of Nursing Education \\ December 2013
}

\begin{abstract}
This report describes the use of team-based learning concepts in an undergraduate nursing applied ethics course using established reporting guidelines. Team-based learning relies on actively engaging students in the learning process through small-group activities that facilitate the development of skills, including concept analysis, critical thinking, and problem solving. Students are divided into teams of five to seven members who collaborate throughout the semester to work through activities that build on ethics concepts introduced through reading and lectures. Nurse educators are challenged to develop educational approaches that will engage students and help them to apply what they learn from the study of ethics to the lived experience of clinical practice. The ultimate goal is to help students to develop into morally sensitive and competent professionals. Team-based learning represents a novel way to teach these skills to undergraduate nursing students.
\end{abstract}

Authors:

Dr. Hickman is Associate Professor, and Dr. Wocial is Adjunct Assistant Professor, Indiana University School of Nursing; Dr. Hickman is also Senior Affiliate Faculty, and Dr. Wocial is also Nurse Ethicist, Fairbanks Center for Medical Ethics, Indiana University Health, Indianapolis, Indiana.

The authors have disclosed no potential conflicts of interest, financial or otherwise.

Address correspondence to Susan E. Hickman, PhD, Associate Professor, Indiana University School of Nursing, 1111 Middle Drive, NU e419, Indianapolis, IN 46202; e-mail: hickman@iu.edu.

This is the author's manuscript of the article published in final edited form as:

Hickman, S. E., \& Wocial, L. D. (2013). Team-based learning and ethics education in nursing. The Journal of Nursing Education, 52(12), 696-700. http://doi.org/10.3928/01484834-20131121-01 


\section{Team-Based Learning and Ethics Education in Nursing}

Beyond the application of knowledge and science lies the moral component of decision making, which demands that even the most technically correct decision be ethically defensible (Pelligrino, Siegler, \& Singer, 1990). Ethics guides practitioners as they navigate the complexities and ambiguities of everyday nursing work (Doane, Pauly, Brown, \& McPherson, 2004). A recent Carnegie Report (Benner, Sutphen, Leonard, \& Day, 2010) places ethics front and center in its call for radical transformation in nursing education and challenges the nursing profession to embrace an education model that integrates knowledge, clinical skills, and everyday ethical comportment. This emphasis on professional ethics sets an expectation that nurses cultivate their moral sensitivity and integrate a strong moral competence into every aspect of nursing practice (Wocial, 2010). To achieve this goal, nurse educators must actively engage students in learning and practicing what it means to be a reflective ethical practitioner. Teaching ethics is more than simply informing students of principles and theories. A key challenge for nurse educators is developing educational approaches that engage students and help them apply concepts they learn from the study of ethics to their clinical experiences. Engaging students in this kind of learning can be challenging and uncomfortable for faculty who are used to providing students with "the right" answer (Hamric, 2001).

Team-based learning (TBL) is an innovative educational strategy that relies on structured, studentcentered activities to enhance learning (Mennenga \& Smyer, 2010; Team-Based Learning Collaborative, n.d.). TBL actively engages students in the learning process with each other, rather than as passive individual learners (Parmelee \& Michaelsen, 2010). Research suggests that the use of TBL can help improve student performance (Zingone et al., 2010) and increase student engagement, as well as satisfaction (Chung, Rhee, Baik, \& A, 2009; Clark, Nguyen, Bray, \& Levine, 2008; Haidet, O'Malley, \& Richards, 2002; Sisk, 2011). TBL has been suggested as a new model of education for nursing (Clark et al., 2008; Sisk, 2011) that helps meet the call to transform nursing education by creating an engaging learning environment for students (Mennenga \& Smyer, 2010).

TBL was originally developed for content with a clear right or wrong answer. However, with some minor modifications, this approach can be adapted for use in teaching more abstract courses, such as applied health care ethics (Chung et al., 2009). TBL helps students learn how to work through challenging ethical dilemmas in a group setting akin to a health care team (Sisk, 2011), which is an especially critical skill when there is disagreement about the best course of action and no clear right or wrong answer (Hamric, 2001). This experience facilitates the development of interpersonal and team skills necessary to work through potentially emotionally charged clinical situations (Clark et al., 2008).

\section{Using TBL to Teach Ethics}

The following is a description of the use of TBL for undergraduate nursing ethics education. The information is structured using guidelines for reporting TBL activities (Haidet et al., 2012).

\section{Context and Scope of TBL Implementation}

For nine semesters, the authors have used TBL to teach Applied Health Care Ethics to undergraduate nursing students during their senior year. Each instructor teaches a separate section of approximately 40 to 50 students per semester, but course content is prepared together. This course uses the four-box method of ethical analysis (Jonsen, Seigler, \& Winslade, 2010) in combination with ethical principles 
(Beauchamp \& Childress, 2008) in discussing challenging clinical dilemmas. The four-box method is a strategy for sorting the elements of a patient's story into four categories: (a) medical indications, (b) patient preferences; (c) quality of life; and (d) contextual features. After sorting, it is easier to recognize the source of ethical tension inherent in a case and to identify the related ethical principles (Sokol, 2008). Formal TBL activities are used in six of 14 didactic classes throughout the semester. To enhance team cohesion and learning, students are asked to work through case-based activities with their teams on days when there are no graded TBL activities. Individual learning is assessed through a case analysis paper and multiple choice or short-answer mid-term and final examinations.

\section{Team Formation}

The number of teams is determined in advance by dividing the number of enrolled students by 6 , with the goal of forming teams composed of 5 to 7 members. Color-coded folders for each team contain a one-page overview of TBL, forms to appeal grading decisions, a blank team score sheet, and evaluation forms for team activities. On the first day of class, TBL principles are reviewed, and students are asked about their prior experiences with TBL. Although students may prefer to work with their friends, it is important that they not be allowed to self-select into teams. Instead, teams are formed transparently with the goal of enhancing the diversity of the whole team and distributing expertise evenly (Parmelee \& Michaelsen, 2010).

The first step in team formation is to ask students with prior ethics education to self-identify and then line up next to each other on the perimeter of the classroom. In advance of class, students are asked to rate their agreement on a 5-point Likert scale with a series of provocative statements relevant to health care ethics, modeled on a values clarification exercise developed by Steele (1979). Sample items include "Health care is a right" and "As a nurse, I must set aside my personal philosophy to support whatever the patient prefers." In class, students are asked to raise their hand to indicate when they strongly agree or disagree with a statement. When a small number of students respond similarly to a specific item, they are asked to join their classmates standing in line on the outside edge of the room. If most students share similar opinions about an item, a different item is selected, as the goal is to maximize the diversity of thought among teammates. When only a small number of students remain seated, they are asked to join the end of the line. Team assignments are determined by a count-off (similar to elementary school gym class) with students counting out loud in order.

The newly formed teams are instructed to sit together, and each team is given a different colored folder with all the materials relevant to team assignments. Students complete a practice individual readiness assessment test (IRAT) and team readiness assessment test (TRAT) focused on content found in the course syllabus and preassigned readings about TBL. The IRAT and TRAT are identical, so that students first have the experience of taking the examination independently and then with their teammates. The practice test provides an opportunity to make explicit the application of TBL principles for the applied ethics class. It also gives students experience with the readiness assessment test (RAT) process and gives the newly formed teams a chance to work together and appeal a deliberately wrong test item when no points for their course grade are at stake (Team-Based Learning Collaborative, n.d.).

Readiness Assurance 
It is important that students complete the assigned prereadings and come to class prepared so that students can spend more time practicing concept application through team activities and discussion. Providing reading objectives helps students focus their reading on important points. The Readiness Assurance Process (RAP) is designed to assess students' knowledge and readiness to move forward with concept application through an 8-item IRAT and TRAT (Michaelsen, Knight, \& Fink, 2004). Multiple choice questions are written using content exclusively from the reading and are based on the identified reading objectives. RAP classes are not announced in advance to encourage more consistent attendance during the semester, as some students opt to skip class if there is no RAP process scheduled because on those days there are no points obtained for participation or test taking.

The RAP process is used as part of either a three-step instructional sequence or a four-step instructional sequence. During classes using the three-step instructional sequence, the following steps are used:

Preparation: Students prepare for class by reading the articles in advance.

Readiness assurance: Class starts with a closed book IRAT followed by a TRAT, time allotted for teams to write an appeal for TRAT questions and opportunity for instructor input or clarification.

Application of course concepts: Application-oriented team activities and problems.

Because ethics content is often complex and readings may not offer clarity about key concepts, the authors recognized that for some of the classes, there is a need to use a four-step instructional sequence. The steps in the four-step sequence are the same as those for the three-step sequence, except that between step 1 (preparation) and step 2 (readiness assurance) faculty provide additional content to complement the reading. Content is focused on deeper discussion and clarification of concepts presented in the reading. Students prefer the four-step model because it provides an opportunity to clarify reading concepts before the individual and team tests.

Immediate Feedback

TBL provides opportunities for immediate feedback to individuals and teams, which is helpful to students as well as course faculty. This strategy helps ensure that students are on track with their learning and that any errors in comprehension are immediately corrected (Parmelee, 2007). IRAT responses are recorded on bubble sheets and turned in before the class breaks into teams to work together on completing the TRATs. IRATs are scored electronically and posted before the next class. Students work together as a team to complete the same test by discussing their responses to each item with teammates and then selecting what they think the correct answer is for each item. After consensus is reached, the team immediately learns whether their responses were correct with the use of Immediate Feedback Assessment Technique (IF-AT ${ }^{\mathrm{TM}}$ ) scratch-off test forms (Epstein Educational Enterprises, 2013). IF-AT forms reveal a star when the correct choice is selected and the silver coating is scratched off. If the team selects the correct answer on the first attempt, a full 10 points are awarded. If they are not correct, they may continue selecting options until the star is revealed. Points are lost for every failed attempt to correctly answer the question (e.g., 6 points are awarded for a correct answer on the second attempt, 3 points for the third attempt, and 1 point for the fourth attempt).

If the team thinks that more than one response option was valid, the team can appeal the question to the instructor. The appeal must include a statement describing the nature of the disagreement and a citation for either a page number from the readings or a specific lecture point. A decision is provided in 
writing by the instructor 1 week later. If the instructor agrees with the reasoning, only team scores for those teams filing an appeal are eligible for score adjustment. Individual test scores are not adjusted.

Accountability is enhanced in two ways. First, teams are required to post their TRAT scores on the classroom whiteboard. This public disclosure promotes friendly competition between teams and also helps prompt slower teams to finish their work. It also allows the instructor to moderate the time allotted to complete this portion of the team exercise. Second, IRAT scores and TRAT scores are added to the score sheet inside the team folder and posted in the electronic course management system. Students are identified by number to protect their privacy. Team members may see scores of team mates but they do not know which score belongs to which team member. This enhances accountability and helps to provide additional information about where a student stands in comparison with teammates.

Sequencing of in-class problem solving. Both RATS and activities are first completed individually and then by the team before discussion within the classroom. This is especially important for the activities because it helps prevent social loafing by students who are content to let their teammates do the thinking. It also enables students to prepare their thoughts before engaging in a discussion about the case.

Four Ss

The four-S structure refers to team activities that contain a significant problem, same problem, specific choice, and simultaneous reporting (Team-Based Learning Collaborative, n.d.). Applied ethics activities are based on cases highlighting clinical ethical dilemmas relevant to nursing practice (Fry \& Veatch, 2006; Veatch, Haddad, \& English, 2010), scholarly articles, the popular press, and the instructors' own experiences as ethics consultants. The team activities highlight and link to concepts presented in the readings and lecture, giving students the opportunity to apply what they learned from course readings and the lecture. The abstract nature of ethics requires problem analysis, the application of concepts, and the evaluation of the potential positive and negative consequences of choices prior to making a decision. This process helps students to identify and consider alternate choices in difficult situations. Tangible outputs include both an individual activity sheet and a brief team paper (i.e., a "Minute Paper") that is completed as a team at the conclusion of class and turned in for review by the instructor. Sample activities are included in Table $A$ (available in the online version of this article).

Each team is asked to work on the same problem and identify specific choices related to the activity. The requirement that a specific choice be made can be challenging in an ethics course, given that the nature of an ethical dilemma is that there are two or more equivalent, conflicting options to resolve the dilemma. There may not be sufficient time or information available for the team to come to agreement, or it may be difficult to identify just one desired action or response. However, this is not dissimilar to real-life situations involving ethical dilemmas when a specific choice must be made.

Intrateam and interteam disagreements are discussed during the subsequent discussion with the entire class. Instructors typically use the objective, reflective, interpretative, decisional (ORID) approach (Michaelsen, Fink, \& Knight, 1997) for facilitating dialogue. A team spokesperson is asked to explain their responses, and other groups are asked to indicate how their thinking was similar or different. After teams have discussed the case and had an opportunity to clarify in their own minds what choices they would make, the class is asked to weigh in on the activity one last time. Students are asked to stand up 
and move around the room ("voting with their feet") to indicate their own opinion about how best to resolve the ethical dilemma. For example, students who would make a similar recommendation are asked to stand at the front of the room, whereas students who disagree with the recommendation stand at the back of the room.

Incentive Structure

The RAP is used in 6 of 14 ethics classes, including the first class, during which no points for the RAP are earned; these activities constitute 50 of the 200 possible course points. In traditional TBL, students are engaged in owning the TBL activities by participating in assigning grade weights to the four elements of TBL (Michaelsen et al., 2004). However, in our experience, students quickly figured out how to weigh the elements so their individual contributions count for the fewest points possible; as a result, students are no longer offered this option. The assigned point values are as follows: IRAT ( 20 points/4 points for each of the five tests); TRAT ( 20 points/4 points each); team activity (5 points/1 point each); and peer evaluation ( 5 points/2.5 points each). In traditional TBL, student peer evaluations are considered in assigning points for grading. The applied ethics students were reluctant to honestly evaluate peers, not wishing to be responsible for teammates losing points. As a result, the peer evaluation grade is based on completion of the evaluation, rather than on the team's evaluation of each member (see the Peer Review section). This change has resulted in more honest evaluations as evidenced by a wider variety of scores given to peers and more specific comments provided on individual performance of peers.

When a student misses a RAP day due to an excused absence, this creates some special challenges. It is not possible for a student to make up a team-based activity, yet the loss of points can impact the overall course grade. To mitigate the effect of an excused absence, students are allowed to earn partial credit with a make-up activity. Students create multiple choice test items from the course readings for the day they were absent. The students must first identify why they believe the content for their written question is important and include a citation to support the material in the question. Each question must contain four potential response options, and students must identify which option they feel is the correct answer.

\section{Peer Review}

On the first day of class, newly formed teams work together to identify the three most important traits of a desirable team-mate (e.g., comes prepared, participates in discussion, is respectful). Each team's list is posted on the board and discussed until the class list is whittled down to five to seven key traits. These are then used as the criteria for peer evaluation twice during the semester. Students are asked to anonymously evaluate each of their team members using these criteria on a scale of 0 (poor) to 10 (excellent) and provide both appreciative comments and respectfully worded critiques about how team members can more positively contribute to the success of the team. Ideally, students do not assign the same score to each team member, although this is difficult to enforce and there is great creativity about how to avoid giving anyone a "bad" review. The quantitative and written peer feedback is compiled and provided in a summarized format to each student twice per semester.

Analysis

The instructors' experiences with TBL suggest that it reinforces the three components of moral competence: moral perception, moral judgment, and moral behavior. Competence is reflected in 
generally highs scores on individual RATS and consistently higher team RAT scores, demonstrating mastery of course concepts. Moral perception and judgment is reflected in students' responses and discussions around team activities, which becomes increasingly sophisticated and nuanced as the semester proceeds and their familiarity with core concepts increases. Moral development is demonstrated through the depth of reflection in the case analysis papers, in which students are asked to identify and analyze an ethical dilemma from their clinical experience. Since using TBL strategies, the case analysis assignment quality has improved, as evidenced by richer case presentations, greater command of ethics concepts, and more complex application of concepts to clinical scenarios. The inclass voting with their feet activities, although not real life, provides students and faculty with the opportunity to reflect on moral behavior when it comes to what nurses do when faced with ethically challenging situations.

Although it is not possible to directly evaluate behavior, students hold their peers accountable for their contributions to team activities on peer evaluations. When activities require students to vote with their feet, the students are given an opportunity to stand up for what they believe is the right answer, which reflects on their potential for moral action in ethically challenging situations. Overall, course evaluations are high (greater than 4 on a scale of 0 to 5 , with 5 being the highest), and students routinely comment that they find TBL to be a helpful strategy for learning about ethics.

\section{Conclusion}

Within nursing, there is a paradigm shift away from a passive to a more active learner approach (Brown, Kirkpatrick, Mangum, \& Avery, 2008). TBL uses concept analysis, critical thinking, and problem solving to actively engage the learner, which is especially important in ethics education (Hamric, 2001). In addition, the use of teams may translate well into the use of TBL for interprofessional ethics education. The application of learning concepts built into TBL methods reinforces the three components of moral competence-moral perception, moral judgment, and moral behavior (Jormsri, Kunaviktikul, Ketefian, \& Chaowalit, 2005). Ultimately, this approach helps to prepare new nurses who are able to embody everyday ethical comportment. 


\section{References}

American Nurses Association. (2008). Code of ethics for nurses with interpretative statements. Silver Spring, MD: Author.

Beauchamp, T.L. \& Childress, J.F. (2008). Principles of biomedical ethics (6th ed.). New York, NY: Oxford University Press.

Benner, P., Sutphen, M., Leonard, V. \& Day, L. (2010). Educating nurses: A call for radical transformation. San Francisco, CA: Jossey-Bass.

Brown, S.T., Kirkpatrick, M.K., Mangum, D. \& Avery, J. (2008). A review of narrative pedagogy strategies to transform traditional nursing education. Journal of Nursing Education, 47, 283-286.

doi:10.3928/01484834-20080601-01

Chung, E.K., Rhee, J.A., Baik, J.H. \& A, O.S. (2009). The effect of team-based learning in medical ethics education. Medical Teacher, 31, 1013-1017. doi:10.3109/01421590802590553

Clark, M.C., Nguyen, H.T., Bray, C. \& Levine, R.E. (2008). Team-based learning in an undergraduate nursing course. Journal of Nursing Education, 47, 111-117. doi:10.3928/01484834-20080301-02

Doane, G., Pauly, B., Brown, H. \& McPherson, G. (2004). Exploring the heart of ethical nursing practice: Implications for ethics education. Nursing Ethics, 11, 240-253. doi:10.1191/0969733004ne692oa

Epstein Educational Enterprises. (2013). Immediate Feedback Assessment Technique (IF-AT). Retrieved November 12, 2013, from http://www.epsteineducation.com/home/about/default.aspx

Fry, S.T. \& Veatch, R.M. (2006). Case studies in nursing ethics (3rd ed.). Sudbury, MA; Jones and Bartlett.

Haidet, P., Levine, R.E., Parmelee, D.X., Crow, S., Kennedy, F., Kelly, P.A. \& Richards, B.F. (2012). Perspective: Guidelines for reporting team-based learning activities in the medical and health sciences education literature. Academic Medicine, 87, 292-299. doi:10.1097/ACM.0b013e318244759e

Haidet, P., O'Malley, K.J. \& Richards, B. (2002). An initial experience with "team learning" in medical education. Academic Medicine, 77, 40-44. doi:10.1097/00001888-200201000-00009

Hamric, A.B. (2001). Ethics development for clinical faculty. Nursing Outlook, 49, 115-117. doi:10.1067/mno.2001.116157

Jonsen, A.R., Seigler, M. \& Winslade, W.J. (2010). Clinical ethics: A practical approach to ethical decisions in clinical medicine (7th ed.). New York, NY: McGraw Hill.

Jormsri, P., Kunaviktikul, W., Ketefian, S. \& Chaowalit, A. (2005). Moral competence in nursing practice. Nursing Ethics, 12, 582-594. doi:10.1191/0969733005ne828oa

Mennenga, H.A. \& Smyer, T. (2010). A model for easily incorporating team-based learning into nursing education. International Journal of Nursing Education Scholarship, 7, 1-14. doi:10.2202/1548-923X.1924

Michalesen, L.K., Fink, L.D. \& Knight, A. (1997). Designing effective group activities: Lessons for classroom teaching and faculty development. In DeZure, D. (Ed.), To improve the academy: Resources 
for faculty, instructional and organizational development (Vol. 16, pp. 373-398). Stillwater, OK: New Forums Press and the Professional and Organizational Development Network in Higher Education.

Michaelsen, L.K., Knight, A.B. \& Fink, L.D. (2004). Team-based learning: A transformative use of small groups in college teaching. Sterling, VA: Stylus.

Parmelee, D.X. (2007). Team-based learning in health professions education: Why it is a good fit? In Michelsen, L.K., Parmalee, D.X., MacMahon, K.K., Levine, R.E. \& Billings, D.M. (Eds.), Team-based learning for health professions education: A guide to using small groups for improving learning (pp. 3-8). Sterling, VA: Stylus.

Parmelee, D.X. \& Michaelsen, L.K. (2010). Twelve tips for doing effective team-based learning (TBL). Medical Teacher, 32, 118-122. doi:10.3109/01421590903548562

Pellegrino, E.D., Siegler, M. \& Singer, P.A. (1990). Teaching clinical ethics. Journal of Clinical Ethics, 1, 175-180.

Sisk, R.J. (2011). Team-based leaning: Systematic research review. Journal of Nursing Education, 50, 665-669. doi:10.3928/01484834-20111017-01

Sokol, D.K. (2008). The "four quadrants" approach to clinical ethics case analysis: An application and review. Journal of Medical Ethics, 34, 513-516. doi:10.1136/jme.2007.021212

Steele, S.M. (1979). Values clarification in nursing. New York, NY: Appleton-Century-Crofts.

Team Based Learning ${ }^{\mathrm{TM}}$ Collaborative. (n.d.) Retrieved from http://www.teambasedlearning.org

Veatch, R.M., Haddad, A.H. \& English, D.C. (2010). Case studies in biomedical ethics: Decision-making, principles, and cases. New York, NY: Oxford University Press.

Wocial, L.D. (2010). Nurturing the moral imagination: A reflection on bioethics education for nurses. Diamatros: An Online Philosophy Service, (25), 92-102. Retrieved from

http://www.diametros.iphils.uj.edu.pl/?l=2\&p=anr26\&m=25\&if=0\&ii=24\&ik=25\&ij=278

Zingone, M.M., Franks, A.S., Guirguis, A.B., George, C.M., Howard-Thompson, A. \& Heidel, R.E. (2010). Comparing team-based and mixed active-learning methods in an ambulatory care elective course. American Journal of Pharmaceutical Education, 74, 160. doi:10.5688/aj7409160 


\section{Table A}

\section{Sample Team Activity 1: Ethical Challenges and the Nursing Code of Ethics}

Direction: Below is a list of challenges $(A-G)$ that illustrate ethical choices nurses make on a regular basis. Identify which provision(s) in the Code of Ethics for Nursing (American Nurses Association, 2008) for nursing offer guidance to the nurse in determining the correct thing to do. In each case, identify where the conflict lies (what is the source of tension) and explain your reasoning.

NOTE: There are NINE provisions and only SEVEN challenges. Provisions may be used once, more than once, or not at all. More than one provision may apply to each situation.

Scenario A. You are working in the recovery room and are assigned to care for a patient who just underwent an appendectomy. When the patient is admitted, an armed guard accompanies him. The anesthesiologist explains that the patient is currently incarcerated for child abuse.

a. What is the source of tension or ethical conflict?

b. What impact should this fact about the patient have on the care provided to the patient?

c. What provision(s) of the Code of Ethics support this reasoning?

Scenario B. The attending physician wishes to admit a patient who has an external ventricular drain and neither you nor any other staff member on the unit has ever cared for a patient with this type of device. There is a written policy explaining the functioning of the device. There is another nursing unit with staff trained in the use of this device. That unit has open beds and adequate staff to care for this patient.

a. Will you accept the admission?

b. What will you say when you tell the physician of your decision? (script)

c. What provision(s) of the Code of Ethics support this reasoning?

Scenario $C$. You are in charge of the unit. Your staffing acuity suggests optimum staffing for the unit would be four nurses but, if necessary, you could get by with three. You have four nurses scheduled, but one of them is your best friend. She calls to ask about the numbers because she wants the night off so she can plan for her wedding.

a. Will you give your friend the night off?

b. What will you say when you tell her your decision? (script)

c. What provision(s) of the Code of Ethics support this reasoning?

\section{Team Minute Paper.}

1. Which of the situations described above do you feel would be the most challenging to do the "right thing," and why?

2. Which of the challenges described above do you feel will most often be encountered when you are a nurse in clinical practice? 


\section{Sample Team Activity 2: Pain Management in a Dying Patient}

Oncology nurse Mindy Johnson was assigned Mr. Thomas, a 67 year old man with cancer that had metastasized to his bones and brain who was nearing death. He was moaning loudly and clearly was in a great deal of pain. At the start of her shift, Mindy immediately checked his pain medication orders and was startled to see that this 145 pound man had received 1120 mgs of morphine by continuous infusion over the prior 8 hours in addition to 30mg boluses every 4 hours, prn. She was alarmed at the dose and concerned it might cause respiratory depression. She confirmed the dose with the treating physician, who indicated that Mr. Thomas had been a homeless heroin addict and had developed a high tolerance for opioids as a result. The physician indicated he had increased the bolus to $40 \mathrm{mg}$ and noted that it was time for the prn dose to try to relieve Mr. Thomas' pain. Mindy had never treated a patient on such a high dose of morphine before and was concerned about the size of the bolus. What if the bolus stopped his breathing?

1) What is/are the right versus right choices? What ethical principles/values are in conflict? Defend your answer.

2) Make a recommendation:

a. Should the nurse run the risk of hastening her patient's death to get the desired analgesia?

b. Justify your recommendation.

3) Evaluate your recommendation.

a. What evidence/outcomes would support the "rightness" of the recommendation?

b. Describe how you would evaluate the implementation of the recommendation.

c. How would you know what impact your recommendation had on key stakeholders in this situation?

4) If the patient stopped breathing after Mindy administers a bolus, would this mean her actions are ethically wrong? Why or why not?

5) Do nurses have an obligation to relieve pain no matter the consequences? Explain your response.

Note: Case adapted from Fry \& Veatch (2006) 